\title{
Assessing Participants' Understanding and Voluntariness of Informed Consent in a Clinical Trial in Nigeria
}

Babatunde Adewale $^{1^{*}}$, Theresa Rossouw ${ }^{2}$ and Lizette Schoeman ${ }^{2}$

${ }^{1}$ Public Health Division, Nigerian Institute of Medical Research PMB 2013 Yaba, Lagos, Nigeria

${ }^{2}$ University of Pretoria, Pretoria South Africa

*Corresponding author: Babatunde Adewale, Public Health Division, Nigerian Institute of Medical Research PMB 2013 Yaba, Lagos, Nigeria, Tel: +234 8072775897 ; E-mail: badewale@hotmail.com

Received date: June 16, 2016; Accepted date: July 12, 2016; Published date: July 13, 2016

Copyright: (C) 2016 Adewale B, et al. This is an open-access article distributed under the terms of the Creative Commons Attribution License, which permits unrestricted use, distribution, and reproduction in any medium, provided the original author and source are credited

\begin{abstract}
Background: The tension between the need for research and the possibility of exploitation of participants' vulnerability mandates the development of reliable measures of ensuring that consent is voluntary and sufficiently informed.

Objective: This study assessed research participants' understanding and voluntariness of informed consent in a malaria clinical trial in Lagos, Nigeria. Methods: It was a cross-sectional survey of 75 research participants using validated questionnaires and a forced-choice checklist. Data were analyzed using SPSS V 17.

Results: All the respondents involved in the clinical trial gave consent before they were recruited. Reasons for participation included: opportunity to get treated (28\%); opportunity for diagnosis of ailments $(32 \%)$; to prevent illness (36\%); and to receive news about medical care (4\%). Payment was seen as a potential incentive for participation by $8 \%$ of participants. Almost all the participants $(98.7 \%)$ stated that they understood the information given to them during the consent procedure. However, while this was confirmed for most of the information in the formal assessment of understanding with a forced-choice checklist, only $37 \%$ and $29 \%$ had understood issues concerning randomization of participants and compensation issues on research related injury respectively, and only $13 \%$ could recall that risks associated with the study had been disclosed.

Conclusion: This clinical trial in Nigeria demonstrated no serious threats to understanding and voluntariness. However, voluntariness was influenced by factors based on the benefits participants would receive through their participation, such as access to diagnosis and treatment not available outside the research setting. There is therefore a need to ensure effective communication between the investigator and research participants during the informed consent process to facilitate the participants' right to self-decision to participate in a clinical trial except when incapable of consenting.
\end{abstract}

Keywords: Research participants; Informed consent; voluntariness; understanding; Clinical trial

\section{Introduction}

Respect for the autonomous choice of a person is based on the fundamental ethical principle of respect for persons and respect for human dignity [1]. Personal autonomy ideally encompasses self-rule that is free from both controlling interference by others and from certain limitations, such as inadequate understanding, that prevent meaningful choice. Therefore, a major trait of an autonomous person is the capacity for self-governance, which involves understanding, reasoning, deliberating, managing and choosing independently [2]. Researchers should always inquire in general terms about their participants' wish to receive information and to make decisions, and they should never assume that because a participant belongs to a particular community or culture, he or she affirms that community's worldview and values. The fundamental requirement is to respect a particular person's autonomous choices, whatever they may be, though other principles such as beneficence, non-maleficence and justice should also be taken into consideration. Respect for autonomy is not a mere ideal in health care, it is a professional obligation [3].

The requirement of individual informed consent, which includes disclosure about the procedure, comprehension of the disclosed information, voluntariness, and competence to act, is the manifestation of respect for autonomy in healthcare and research [4]. It is universally recognized as a central component of ethical conduct of research and allows subjects to make informed and voluntary choices to participate or refuse to participate in a project where they will be asked to take risks for the benefit of others [5,6]. The provision of information, comprehension of information and voluntary participation are foundational in the consent discussion [7].

Voluntary decision-making is a challenge in research settings, particularly in developing countries. Medical doctors and researchers occupy positions of authority and patients and participants are often unwilling or unable to challenge or question their opinion. Doctors have credibility and great influence over patients because of the general belief that doctors will always "do good" for their patients. Furthermore, participants are often illiterate, uneducated or gullible and often do not question terms of participation $[8,9]$. The distinction 
between care and research might also not be clearly delineated when the physician is also the researcher [9]. This is exacerbated by the fact that citizens of developing countries are often in vulnerable situations because of their lack of political power, lack of education, unfamiliarity with medical interventions, effects of war, pandemics, famine, extreme poverty or dire need for health care and nutrition [10,11]. It is the dire need of these populations that makes them both appropriate participants of research and especially vulnerable to exploitation [12].

The Nuremberg Code brought informed consent to the forefront of ethical practice in research. In the view of Barsdorf and Wassenaar [10], information disclosure and understanding have been heavily researched with insufficient empirical attention to voluntariness, especially in the developing world. This study therefore assessed the understanding and voluntariness of informed consent in a crosssectional survey of research participants in a malaria clinical trial in Nigeria.

\section{Methodology}

\section{Study design}

The study design was a cross-sectional descriptive analysis of the informed consent process. The study was carried out in a rural community called Ijede, in Ikorodu Local Government Area of Nigeria where there was an ongoing hospital-based anti-malaria clinical trial. The Principal Investigator of the trial and the hospital administrator were approached for permission to interview a sample of the participants involved in the trial. Though the participants did not give a written permission to be re-contacted, they were approachable since they reside in the community where the research was carried out and were sought out through the research participants' records by random sampling. The researchers and administrators were fully informed of the purpose of the study and all attempts were made to foster a mutually beneficial and professional working relationship between the two sets of researchers. In the course of the study, observed involuntariness and misunderstanding of the informed consent document of the clinical trial were reported to the principal investigator of the clinical trial for further management.

\section{Inclusion criteria}

Adults older than 18 years were approached to participate in this study. They all had to be residing in the Ijede community, consented to participation in an anti-malaria trial (either on behalf of themselves or on behalf of a child not older than 5 years) within the last 6-12 months and had to be willing and able to give informed consent for participation in the study.

\section{Methods}

Understanding was assessed in two ways, using the method developed by Lindegger et al. [13]. Participants first completed a questionnaire, which consisted of a forced-choice checklist consisting of true and false options to statements. There were three statements for each component. Participants were then requested to complete a selfreport that was based on seven components, namely: trial aims, eligibility to participate, risk of participating in the trial, risk of falsely believing the test product would protect one from infection and thus increase one's risk behaviour ("false sense of security"), methodological considerations- such as randomization, placebo and blindingcompensation for research-related injury, and the right to withdraw.
Participants were required to estimate their level of personal understanding of each of these components.

Voluntariness was assessed using a questionnaire adapted from Barsdorf \& Wassenaar [10] which was demonstrated to have excellent internal reliability. The questionnaire comprised four sections and a total of 43 questions (Appendix 1). The questionnaire was translated into the local language using the double-back translation method. As recommended by Barsdorf and Wassenaar [10], minor alterations were made to the questionnaire in the framing of questions in order to improve understanding. The process of obtaining informed consent was assessed through questions in section 4 of the semi-structured questionnaire used in this study (Appendix 1).

\section{Sample size}

There were 360 participants in the anti-malaria trial. Assuming a prevalence of involuntariness and misunderstanding of 50\% [10,14], a sample size of 75 was deemed sufficient to adjust for losses and withdrawals, allowing for a power of $80 \%$ and a level of significance of 95\%.

\section{Data analysis}

Completed questionnaires were pre-cleaned, coded and analysed using SPSS for windows (SPSS inc., 1999). Basic descriptive statistics (such as means, proportions, frequencies and ranges) and limited analysis (correlation and chi-squares) of the possible associations between the predictor variables and the outcome variables (involuntariness and inadequate understanding) were performed.

\section{Ethical considerations and approval}

The participants were informed about the possible benefits and risks involved in participating in the study. They were further assured of the confidentiality of the information given, and also of their right to decline to participate or withdraw at any time without penalty. After participants confirmed that they understood all the information and were willing to participate in the study, they signed the informed consent document. Confidentiality was assured by not using any personal identifiers in the collection, analysis or reporting of the data. The proposal was approved by ethics committees of the University of KwaZulu-Natal (Approval Number: HSS/0247/2010 M) and the Nigerian Institute of Medical Research. Approval was obtained before the commencement of the project.

\section{Results}

\section{Demographic data of respondents}

All 75 persons invited to participate in this study, agreed to do so. Participants had a mean age of $36.5 \pm 10.3$ years (range 18-57 years) and the majority-53 (70.7\%) and 64 (85.3\%) respectively- were female and married. Their educational backgrounds ranged from no education-5 (6.6\%), to primary-11 (14.7\%) -, secondary-48 (64\%) and tertiary-11 (14.7\%) education. The majority - 40 (53.3\%) - were involved in trading as a profession.

\section{Informed consent process}

All the respondents knew they were taking part in a malarial clinical trial and all had given consent before being recruited into the study. 
Page 3 of 6

The majority-67 (89.3\%) gave written consent while 8 participants (10.7\%) gave verbal consent. The majority of respondents- $74(98.7 \%)$ stated that they were not allowed to go home with the informed consent document, while $1(1.3 \%)$ respondent said there was no need to go home with the informed consent document.

\section{Understanding of informed consent}

Almost all the respondents- 74 (98.7\%) claimed they had understood the information given to them during the consent procedure and they had all given consent without consulting anybody outside the medical field. One of the respondents, identified to be a male aged between 45-49 years with secondary education and working as a civil servant, was the only one who stated that he did not understand the information given during the informed consent process. However, in the assessment of understanding using the forced-choice checklist for 66 of the participants, 42 (63.6\%) of the participants stated that they had not understood the concept of randomization of participants in the clinical trial and $47(71.2 \%)$ did not understand issues of compensation for research related injury.

The comprehension score for all six major aspects of the informed consent document ranged from 19 (28.8\%) for the comprehension of issues about compensation for research related injury to $100 \%$ for issues concerning eligibility to participate and the trial aim (Figure 1). The percentages of correct responses were greatest for questions dealing with the background information of the project and the rights of participants.

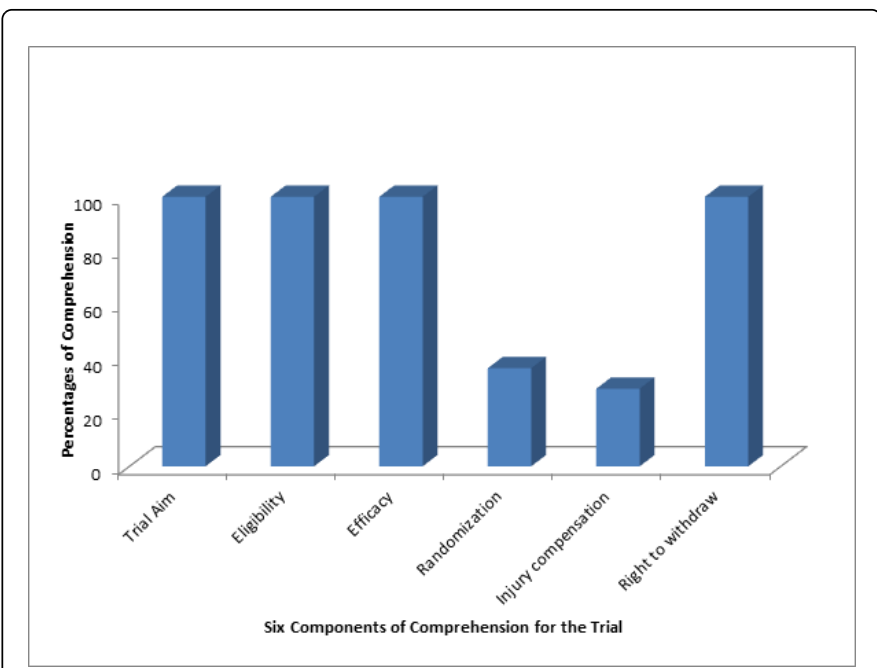

Figure 1: Comprehension score of participants using forced-choice checklist.

Three (4.0\%) of the respondents were not given the opportunity to ask questions before consenting, but all the others said they had been given the opportunity to ask questions. Only 10 (13.3\%) of the respondents said the risks involved in participation in the research were disclosed. The risks they remembered were dizziness, drowsiness and weakness. The majority of the respondents- 35 (46.7\%) however claimed that the risks involved in participation were not disclosed to them while a large proportion of the respondents 30 (40.0\%) could not remember if the risks of participation were disclosed or not. Numerous respondents - 67 (89.3\%) were not aware of any unforeseen risks, while only $7(9.3 \%)$ of the respondents knew there might be some unforeseen risks. All the respondents knew they could withdraw from the study at any point without penalty and that people must be given the opportunity to choose whether or not to take part in research.

\section{Voluntariness of informed consent}

Most of the respondents 59 (79.7\%) thought people get involved or are chosen for medical research because they are ill, while the remainder 15 (20.3\%) thought the research participants are volunteers. Their reasons for consenting to be part of the clinical study were because they believed their illness would be diagnosed- 24 (32\%), they were ill- 27 (36\%), they could get treatment for their illness- 21 (28\%) and they heard that people who were ill were treated for free in the study 3 (4\%).

Almost all the respondents- 74 (98.7\%) gave consent immediately after the clinical trial information had been given. The majority of the people thought that they were given enough time to think about the issues- $67(89.3 \%)$ while about $8 \%$ said they were not given enough time. It was very easy for almost all of the respondents- $74(98.7 \%)$ to make a decision about participating in the clinical trial, but for 1 (1.3\%) of the respondents, it was neither easy nor difficult. For those who thought the decision was easy, this was based on the fact that they would access treatment- $60(80.0 \%)$, laboratory testing $10(13.3 \%)$, and because they were ill- 7 (9.3\%).

\section{Factors influencing voluntariness}

According to the respondents, the decision to participate in research could be influenced by illness $30(40.0 \%)$, news about the study- 29 $(38.7 \%)$, and the opportunity to obtain treatment $16(21.3 \%)$. Only 5 $(6.7 \%)$ of the respondents had previously participated in a clinical trial and all the respondents felt there were benefits in participating in a research study. The major benefits mentioned were the opportunity to obtain treatment $71(94.7 \%)$, undergo a diagnostic test- $42(56.0 \%)$, and education on research process and treatment options 7 (9.3\%). Some respondents chose more than one benefit (Figure 2).

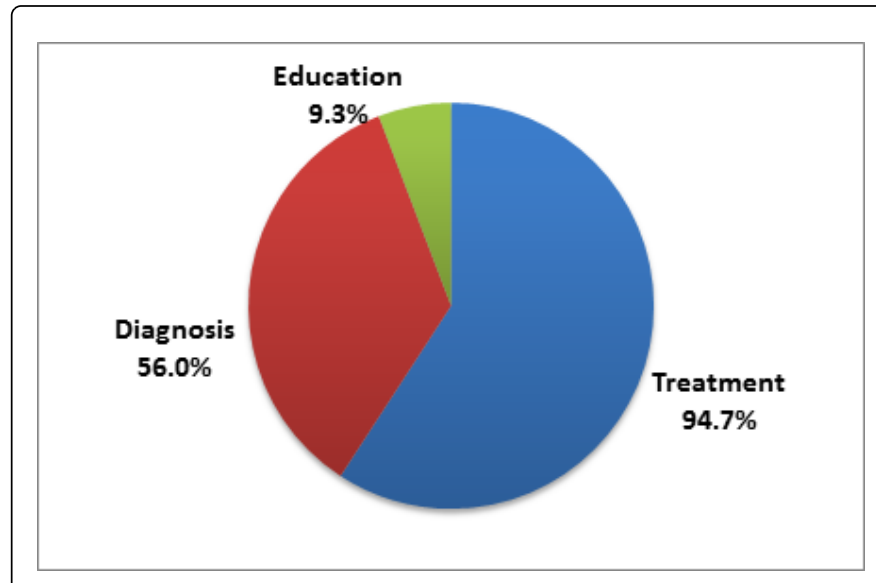

Figure 2: Benefits of participation in research.

The majority of respondents- 73 (97.3\%) stated that they were not paid to participate in the clinical trial. Eight $(10.7 \%)$ of the participants believed that research participants should be paid, though none of them could proffer an amount that they deemed acceptable payment for participation. Less than one-tenth of the respondents- 6 (8.0\%) thought that payment could potentially influence their decision to 
participate in the trial because it would serve as an incentive. The majority of respondents $57(76.0 \%)$ said payment would not, while the rest- $12(16.0 \%)$ could not say if payment would or would not influence their decision to participate.

There was no specific pattern in the age groups of respondents who said payment would affect their participation. Of the six respondents, one each was in the age group 15-19 years, 20-24 years, 35-39 years and 40-44 years, and two were between 25 and 29 years. None were older than 45 years.

There was no significant association between the decision to participate in the study and the age $(\mathrm{p}=0.533)$, sex $(\mathrm{p}=0.342)$, education $(\mathrm{p}=0.078)$, religion $(\mathrm{p}=0.144)$, marital status $(\mathrm{p}=0.239)$, occupation $(\mathrm{p}=0.076)$ and ethnicity $(\mathrm{p}=0.468)$ of the respondents.

\section{Discussion}

This study set out to assess the informed consent process as well as the understanding and voluntariness of informed consent of participants in a clinical trial in a developing world context.

Overall, participants felt that the informed consent process was satisfactory. No major threats to understanding and voluntariness were detected, but a few issues emerged that warrant further attention, most notably, understanding of complex research concepts and risks, as well as the influence of benefits and trust on voluntariness.

Appelbaum et al. [15] stated that informed consent comprises three elements: information, competence and voluntariness. Although most participants in this study stated that they had understood the information contained in the informed consent document, further investigation revealed that the majority did not comprehend complex concepts such randomization and compensation of research-related injury. One of the key issues that impair comprehension is the improper and inappropriate interpretation of terminologies used in clinical trials. There seems to be a need to find a way of explaining these terminologies and concepts in the local language and with relevant examples. Some concepts, such as randomization, do not have a direct local translation that is applicable to the setting. Similarly, concepts such as compensation after research-related injury is still a strange concept to many people in developing countries as participants mostly lack access to legal recourse and health insurance is neither subscribed to nor available in many rural communities.

According to Fitzgerald et al. [16] participants' comprehension improves when information is repeated through many information sessions before consent is given. The choice of personnel involved in the informed consent process plays an important role here. They should have adequate knowledge of the clinical trial and also be able to communicate effectively with the participants. The participants should be allowed enough time to understand all the information and feel free to ask questions about everything that is unclear. Informed consent should be a process and not a once-off information session $[2,16]$.

Lack of understanding of complex research concepts could probably have been mitigated if the participants had been given more time for the informed consent process and if effective communication between the investigator and research participants had been facilitated. It is further possible that allowing participants to go home with the document to discuss it with family members might have improved their levels of understanding of the issues concerned or might even have resulted in informed refusal [17]. The fact that $98.7 \%$ of the respondents stated that they were not allowed to go home with the informed consent document, means that they had not been given the opportunity to draw on the support of family members. Family support is however not always beneficial, as illustrated by Thomas and Latimer [18] and corroborated by Rothchild [19], who documented that the presence of a supportive family member may improve the person's ability to identify and state his or her preferences, whereas the presence of an insensitive or domineering family member may have the opposite result.

It is further worrisome that the majority of participants either could not recall that risks involved in participation had been disclosed to them $(87 \%)$ or were not aware of any risks (89\%). It is not possible to deduce whether risks had in fact not been discussed, or whether this finding reflects poor comprehension on the part of the participants. This is in contrast to the benefits of participation, which participants were able to recall without difficulty and which seemed to have been their major focus. It is also possible that potential benefits might have been strongly emphasized by the researchers during the consent process, in order to encourage participants to enroll. In this study, it seems that the major factor that determined participation was the benefits participants stood to gain by their participation, irrespective of their level of comprehension of the informed consent document and this raises concerns about the voluntariness of participation.

Voluntariness could arguably have been hampered because of the benefits participants stood to gain as a result of their participation, such as better access to diagnosis and treatment of ailments, which would not have been possible outside of the clinical trial due to poor health infrastructure. This is the case in most African countries where there is a dire need for health care because of inadequate public health systems [20]. It seems that most participants believed that clinical treatment received as part of the research study would confer personal benefit. This perception might result in a therapeutic misconception [21], which is the failure of the research participant to appreciate that he or she is being enrolled in a research study and not in standard clinical care. Accordingly, Appelbaum et al. [22] recommend that one of the elements that should be made clear to participants before they consent to participate in research is the experimental and impartial nature of research. Participants should understand that the belief that their interests will be the main priority of the researcher may be inaccurate in such a context.

All the research participants however indicated that they had been given the opportunity to choose whether or not to participate in the clinical trial as a precursor to their involvement and perceived their participation as voluntary. One may however argue that, although the perceived level of voluntariness was high, the level of voluntariness might have been diminished by the influence of symptoms of illness and pressures intrinsic to their setting [23,24]. Roberts [21] identified that severe pain is one of the physical symptoms that arises as a result of illness and has a profound impact on voluntariness. This has been demonstrated in studies in which adequate pain control radically changed the consent decision of patients, including end-of-life-care preferences [25]. The degree of physical dependence a person experiences e.g. the inability to feed oneself or to attend to one's own hygiene - due to pain or debilitation also affects a person's ability to make and insist upon choices [26].

It is interesting to note that none of the variables such as age, sex, education, religion, marital status, occupation or ethnicity was associated with decisions of participants to participate in the clinical trial. This is in contrast to the study of Barsdorf and Wassenaar [10], where it was noted that education influenced perceived voluntariness. 
Page 5 of 6

This disparity might be explained by the very high level of perceived voluntariness documented in our study.

Although not explicitly tested, an element of trust might also have impacted on participants' decisions to enroll in the clinical trial. The research team of the clinical trial had been operative in the community for many years and had built up a relationship of trust with the local leaders $[27,28]$. The researchers in this study gained access to the community and enjoyed their cooperation through the rapport that had been created by this interaction. This is unlike the study of Barsdorf and Wassenaar [10], who reported a problem with trust due to the experience of Black Africans (mostly) during the apartheid regime, which was still fresh in their memories. There was therefore impairment of perceived and experienced voluntariness of mostly the Black South African participants, who perceived volunteering as a form of passive compliance rather than an active wish to participate. This was contrary to the experience in this study where voluntariness seemed to have been augmented by the relationship of trust.

\section{Limitations}

The generalizability of the current finding is limited by the relatively small sample size. Since those who took part in the study were volunteers in the clinical trial, the study was unable to capture why people may not want to take part in clinical trials. The clinical trial enrolled participants from a large area and the remoteness made accessibility difficult. Finally, the time interval of about three months between the time consent was given for the clinical trial in this study could also have influenced what the participants were able to remember.

\section{Conclusion}

In this study about the understanding and voluntariness of research participants in Nigeria, it was found that even though participants' perceptions of their understanding of the informed consent document and voluntariness of participation were high, there were concerns regarding their understanding of complex research concepts and risks, as well as the influence of benefits on voluntariness. The study identified the need to improve the informed consent process by giving enough time to participants to ask questions and allow them the opportunity for consultation with their family members if they so wish. It further highlighted the need for local interpretation of complex research issues, such as randomization and compensation, and the necessity of employing well-trained personnel who are familiar with both the research process and the local environment.

This study showed that although informed consent was without the deliberate, specific influence of any individual, there were other factors that played major roles in the participants' decision to take part in the clinical trial. The results of this study showed that the state of health of the participants and the benefits of treatment they stood to gain through their participation, acted as motivational factors while other factors such as age, sex, education, marital status and ethnicity did not influence the participants' decision to take part in the clinical trial.

There is therefore a need for the protection of the vulnerability of participants in this regard. This could be in the form of allowing adequate time to enable the improvement of participants' understanding of the consent form, using innovative ways of explaining complex concepts such as randomization, and providing the necessary support to facilitate participants' right to self-decision.

\section{Acknowledgements}

The project described was supported by Award Number R25TW001599 from the Fogarty International Center to the South African Research Ethics Training Initiative (SARETI). The content is solely the responsibility of the authors and does not necessarily represent the official views of the Fogarty International Center or National Institutes of Health.

\section{References}

1. Lindegger GC, Bull S (2002) Ensuring valid consent in a developing country context. Sci Dev 1:1.

2. Okonta PI (2015) Obstetrics and gynaecology residents' knowledge of the informed consent Process and its practice in their training institutions. Niger J Clin Pract 18: 445-52.

3. Beauchamp TL, Childress JF (2009) Principles of biomedical ethics (6th edn.) Oxford University Press, New York.

4. (2013) Declaration of Helsinki: Ethical principles for medical research involving human subjects. World Medical Association.

5. Cahana A, Hurst SA (2008) Voluntary Informed Consent in research and clinical care: An update. Pain Pract 8: 446-451.

6. Emanuel EJ, Wendler D, Grady C (2000) What makes clinical research ethical? JAMA 283: 2701-2711.

7. Marshall PA (2006) Informed consent in international health research. J Empir Res Hum Res Ethics 1: 25-42.

8. Molyneux CS, Wassenaar DR, Peshu N, Marsh K (2005) 'Even if they ask you to stand by a tree all day, you will have to do it (laughter)...!': Community voices on the notion and practice of informed consent for biomedical research in developing countries. Soc Sci Med 61: 443-454.

9. Falusi A (2008) Consent seeking and principles of distributive justice in field laboratory health projects in non-literate societies. Ethics of Public $\mathrm{H}$ ealth Research in Africa 1: 29-34.

10. Barsdorf NW, Wassenaar DR (2005) Racial differences in public perceptions of voluntariness of medical research participants in South Africa. Soc Sci Med 60: 1087-1098.

11. Minnies D, Hawkridge T, Hanekom W, Ehrlich R, London L et al. (2008) Evaluation of the quality of informed consent in a vaccine field trial in a developing country setting. BMC Medical Ethics 9:15.

12. Glantz LH, Annas GJ, Grodin MA, Mariner WK (2001) Research in developing countries: Taking "benefit" seriously. In: Teays W, Purdy L (Edn.), Bioethics, Justice and Health care, Wadsworth, Belmont, pp. 261-267.

13. Lindegger G, Milford C, Slack C, Quayle M, Xaba X, et al. (2006) Beyond the checklist: Assessing understanding for HIV vaccine trial participation in South Africa. J Acquir Immune Defic Syndr 43: 560-566.

14. Bhansali S, Shafiq N, Malhotra S, Pandhi P, Singh I, et al. (2009) Evaluation of the ability of clinical research participants to comprehend informed consent form. Contemp Clin Trials 5: 427-430.

15. Appelbaum PS, Lidz CW, Klitzman R (2009) Voluntariness of consent to research: A conceptual model. Hasting Cent Rep 39: 30-39.

16. Fitzgerald DW, Marotte C, Verdier RI, Johnson WD, Pape JW (2002) Comprehension during informed consent in a less-developed country. Lancet 360: 1301-1302.

17. Tindana PO, Singh JA, Tracy CS, Upshur REG, Daar AS, et al. (2007) Grand challenges in global health: Community engagement in research in developing countries. PLoS Med 4: e273.

18. Thomas JE, Latimer EJ (1984) When families cannot "let go": ethical decision-making at the bedside. CMAJ 141: 389-391.

19. Rothchild E (1994) Family dynamics in end-of-life treatment decisions. Gen Hosp Psychiatry 16: 251-258.

20. Lynöe N, Hyder Z, Chowdbury M, Ekström L (2001) Obtaining informed consent in Bangladesh. N Eng J Med 344: 460-461. 
Citation: Adewale B, Rossouw T, Schoeman L (2016) Assessing Participants' Understanding and Voluntariness of Informed Consent in a Clinical Trial in Nigeria. J Clin Res Bioeth 7: 1000279. doi:10.4172/2155-9627.1000279

Page 6 of 6

21. Roberts LW (2002) Informed consent and capacity for voluntarism. Am J Psychiatry 159: 705-712.

22. Appelbaum PS, Lidz CW, Meisel A (1987) Informed consent: Legal theory and clinical practice. Oxford University Press, New York.

23. Glick KL, Mackay KM, Balasingam S, Dolan KR, Casper-Isaac S (1998) Advance directives: barriers to completion. J N Y State Nurses Assoc 29: 4-8.

24. Moreno J, Caplan AL, Wolpe PR (1998) Project on Informed Consent, Human Research Ethics Group: Updating protections for human subjects involved in research. JAMA 280: 1951-1958.

25. Ganzini L, Lee MA, Heintz RT, Bloom JD (1993) Depression, Suicide, and the right to refuse life-sustaining treatment. J Clin Ethics 4: 337-340.
26. Pearlman RA, Cain KC, Patrick DL, Appelbaum-Maizel M, Starks HE, et al. (1993) Insights pertaining to patient assessments of states worse than death. J Clin Ethics 4: 33-41.

27. Agomo P, Mustapha R, Omoloye B, Okechukwu A, Mafe A, et al. (2007) Efficacy and Safety of Artesunate +Mefloquine (Artequin) in the Treatment of Uncomplicated Falciparum malaria in Ijede Community, Ikorodu LGA, Lagos State, Nigeria. J Med Sci 7: 816-824.

28. Nyika A, Chilengi R, Ishengoma D, Mtenga S, Thera MA, et al. (2010) Engaging Diverse Communities Participating in Clinical Trials: Case Examples from Across Africa. Malar J 9: 86. 